\title{
Análise da Trajetória de Robô Móvel Utilizando Odometria como Técnica para Navegação em Ambientes de Robótica Educacional
}

\author{
Marcel L. Rios ${ }^{1,2}$, José F. Magalhães Netto ${ }^{2}$ \\ ${ }^{1}$ Instituto Federal de Rondônia - Campus Porto Velho Calama \\ (IFRO) - Porto Velho, RO - Brasil \\ ${ }^{2}$ Programa de Pós-Graduação em Informática - Universidade Federal do Amazonas \\ (UFAM) - Manaus, AM - Brasil \\ marcel.rioseifro.edu.br, jnettodicomp.ufam.edu.br
}

\begin{abstract}
This work performs analysis the trajectory of a mobile robot with wheels on an plan environment of Educational Robotics using a method of relative location, Odometry. The objective is to support the evaluation of robotic behavior in complex tasks of Educational Robotics. The experiments were conducted on ovals, where the mobile robot performed the capture the respective rotational values in order to calculate the odometry to map and reconstruct the path taken. The results showed that the trajectory estimated Odometry obtained by a small margin of error due to the limitation of the sensors and actuators of the mobile robot, and may be cumulative depending on the distance traveled.
\end{abstract}

Resumo. Este trabalho realiza a análise da trajetória de um robô móvel com rodas em um ambiente plano de Robótica Educacional utilizando um método de localização relativa, a Odometria. O objetivo do trabalho é subsidiar a avaliação do comportamento robótico em tarefas complexas de Robótica Educacional. Os experimentos foram realizados em circuitos ovais, onde o robô móvel realizou a captura de seus respectivos valores rotacionais com a finalidade de calcular a Odometria para mapear e reconstruir o trajeto realizado. Os resultados mostraram que a trajetória estimada por Odometria obteve uma pequena margem de erro decorrente da limitação dos sensores e atuadores do robô móvel, podendo ser acumulativo dependendo da distância percorrida.

\section{Introdução}

A utilização da Robótica Educacional vem sendo utilizada como mecanismo interdisciplinar em diversas instituições de ensino, promovendo tarefas e desafios com diversos níveis de complexidade. Os projetos de robótica na educação buscam incentivar o aprendizado e estimular o interesse do aluno, contribuindo para o processo de ensino-aprendizagem.

A popularização de brinquedos programáveis simplificou a construção de modelos robóticos, incentivando o surgimento de projetos de pesquisa na área da Informática na Educação. Tais projetos, integrando robôs e noções de programação na apresentação de conteúdo aos alunos, buscam avaliar o impacto e a influência dessas tecnologias no aprendizado [Heinen et al. 2015]. 
A robótica se destaca como ferramenta educacional atrativa e estimulante, visto que o assunto desperta interesse em todas as idades. A sua aplicação, dentro do ambiente escolar, pode trazer benefícios tanto para o professor quanto para o aluno, oferecendo oportunidades de experimentar novos ambientes de aprendizagem, proporcionando atividades que além de desafiar, tende a motivar o aluno, uma vez que utiliza da criatividade e lógica do aluno na apresentação de soluções de hardware e software, a partir da resolução de uma situação-problema [Fiorio et al. 2014].

Um forma de avaliar o aprendizado do aluno é por meio do comportamento da plataforma robótica perante uma determinada tarefa, geralmente são robôs móveis com rodas. Embora exista uma grande variedade de metodologias para a estimação da posição e trajetória do robô em um ambiente, a odometria simples é um dos métodos de localização mais utilizados em estruturas de locomoção a rodas. No entanto, erros de dimencionamento, escorregamentos e imperfeições na superfície de contato pneu-solo fazem com que a técnica se torne consideravelmente imprecisa, fazendo da Odometria um método que pressupõe planaridade do movimento [Martins et al. 2011].

Atualmente, com o advento de novas Tecnologias da Informação e Comunicação (TIC), diversas modalidades de desafios robóticos vêm surgindo, tanto na educação presencial como na educação a distância. Tais desafios carecem de métodos que possam computar e analisar o comportamento robótico. Nesse contexto, o trabalho proposto utilizou um ambiente de tarefa em Robótica Educacional para desenvolver a trajetória de um robô móvel. Para monitorar o comportamento robótico, foi adotado um método de localização relativa, a Odometria. Os resultados demonstram que, em ambientes internos e com restrição de tamanho, a odometria se mostrou um método bastante eficiente. No entanto, longas distâncias e fatores mecânicos podem gerar erros acumulativos, fazendo com que os cálculos de Odometria necessitem de correções.

O restante do artigo está organizado da seguinte forma: a Seção 2 apresenta uma contextualização sobre navegação de robôs móveis, descrevendo os os trabalhos relacionados a métodos de localização relativa com Odometria; a Seção 3 contempla os materiais e métodos adotados na realização dos experimentos práticos; a Seção 4 apresenta os resultados e discussão da pesquisa; e a Seção 5 apresenta a conclusão do trabalho.

\section{Navegação de Robôs Móveis}

Um robô móvel é um agente autônomo capaz de extrair informações do ambiente e utilizar esse conhecimento do mundo para deslocar-se com segurança de modo significativo e intencional, atuando e executando tarefas. Os robôs móveis são muito mais versáteis, pois não precisam estar fixados a uma célula de trabalho como os robôs industriais convencionais, sendo utilizados em tarefas onde não existam limites geográficos, movimentando-se por meio de pernas, rodas, esteiras, por empuxo ou flutuação [Pio et al. 2006].

Os robôs móveis têm um lugar de destaque, pois não ficam restritos a um único local de operação e, por conta disto, têm uma aplicabilidade e versatilidade muito maior que os robôs manipuladores, que são mais frequentes nas fábricas. Por conta desta maior versatilidade, muitas destas aplicações, frequentemente, demandam um alto grau de precisão e exatidão dos robôs durante a execução das tarefas atribuídas, onde estimadores podem ser aplicados como forma de aumentar a confiabilidade dos valores de tais variáveis, medidos direta ou indiretamente pelo sistema de sensoriamento do robô [Carvalho et al. 2009]. 
O mapeamento robótico tem sido largamente explorado dentro da robótica e inteligência artificial nas últimas décadas. No contexto de robótica móvel, a localização é um dos temas mais abordados, sendo esta uma atividade fundamental para o bom desempenho do robô em suas missões de navegação, e é definida pela estimativa probabilística da pose (posição e orientação) de um robô [Thrun et al. 2005].

Localizar um robô móvel consiste em determinar a sua posição e orientação no espaço em um determinado instante de tempo. Os métodos de localização de robôs móveis podem ser classificados em duas grandes categorias: Métodos de Localização Relativa e Métodos de Localização Absoluta [Borenstein et al. 1996]. Os métodos de localização relativa utilizam as localizações obtidas em instantes anteriores para estimar a localização atual do robô, como a odometria. Já os Métodos de Localização Absoluta utilizam apenas as informações atuais dos seus sensores para determinar a localização do robô em relação a um referencial fixo absoluto, como os marcos artificiais/naturais [Bezerra et al. 2003].

\subsection{Método de Localização Relativa - Odometria}

A odometria, devido ao seu baixo custo, é um método de localização bastante utilizado em robôs móveis com rodas. O método de odometria consiste na determinação da posição e orientação do robô através da integração dos deslocamentos incrementais de suas rodas, medidos a partir de um referencial fixo. Para medir o deslocamento do robô é necessário a utilização de um sensor que possa medir a rotação das suas rodas. Em aplicações envolvendo robôs móveis, um tipo de sensor de odometria bastante utilizado é o codificador ou encoder ótico [Bezerra et al. 2004].

No entanto, a localização do robô calculada a partir dos encoders é passível de erros associados, sendo estes representados por uma região elíptica ao redor da posição atual do robô, conforme demonstra a Figura 1. Essa região indica o grau de incerteza da odometria, aumentando juntamente com a distância percorrida pelo robô [Tonouchi et al. 1994].

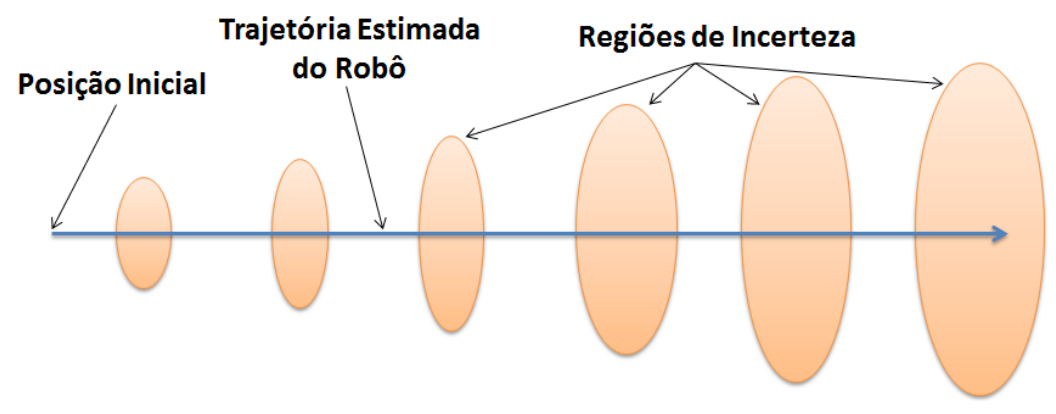

Figura 1. Incerteza de Posição com Odometria [Tonouchi et al. 1994].

Na odometria os deslocamentos angular e linear são calculados a partir da medição rotacional em cada roda, podendo utilizar um disco com furos, geralmente acoplado diretamente ao eixo do motor e um par emissor/receptor de infravermelho. Os principais problemas dos métodos baseados em odometria consistem no fato de que, para se obter a precisão necessária para aplicações em robótica, são necessários encoders de alta resolução, os quais podem aumentar significativamente os custos de implementação e que, em odometria, o erro é acumulativo [Carvalho et al. 2009]. 
V Congresso Brasileiro de Informática na Educação (CBIE 2016)

Anais do XXVII Simpósio Brasileiro de Informática na Educação (SBIE 2016)

Especificamente para o Lego Mindstorms NXT, a odometria pode ser calculada a partir das rotações obtidas pelo servo-motores ou a partir de sensores de rotações. $\mathrm{O}$ sensor de rotação é um tipo de sensor muito útil, pois possui um codificador óptico (encoder), similar aos dos servo-motores do NXT. O sensor de rotação possui um orifício para colocar um eixo, do qual a posição angular é medida [Benedettelli 2007].

Nesse contexto, visando analisar a trajetória do robô no desenvolvimento de atividades em ambientes de Robótica Educacional, foi adotado o Kit Lego Mindstorms NXT 2.0 para implementação do método de localização relativa com Odometria, com a finalidade de analisar o caminho percorrido pelo robô móvel, provendo um mecanismo para monitorar o comportamento robótico.

\section{Materiais e Métodos}

Os experimentos foram realizados em um cenário interno, um ambiente de tarefa de Robótica Educacional medindo 120x90 cm. O ambiente não possui qualquer restrição para navegação, não possuindo redutores de velocidades, nem obstáculos ou marcos naturais. O robô móvel utilizado nos experimentos trata-se de um robô (LEGO Mindstorms NXT 2.0) uniciclo, com acionamento diferencial, não-holonômico, projetado por [Kee 2015]. Conforme demonstra a Figura 2, ao robô foi acoplado uma pequena garra para a inserção do pincel para marcação de trajetória.

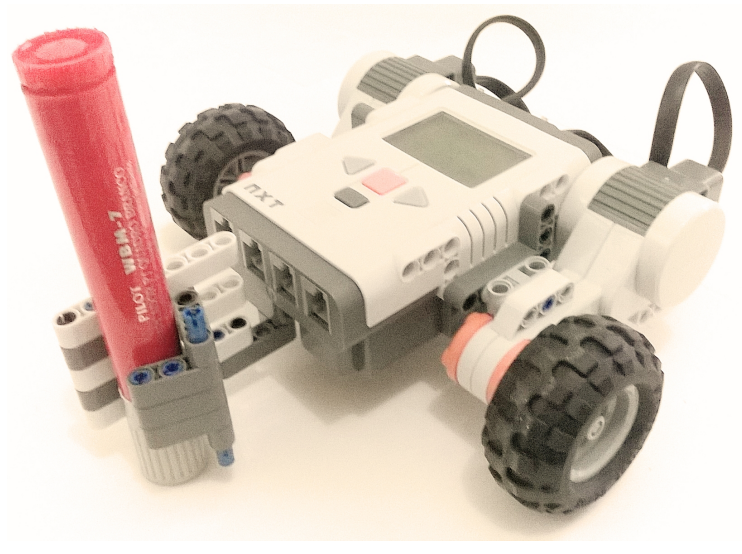

Figura 2. Robô Móvel Utilizado nos Experimentos.

O objetivo dos experimentos foi a realizar a análise de trajetórias em circuitos fechados. Sempre na primeira trajetória, no circuito fechado, o robô faz a captura dos valores obtidos por meio dos sensores de rotação (encoders incrementais). Em seguida, o mesmo deve estimar e refazer a mesma trajetória através da Odometria. Dessa forma, foi possível comparar a trajetória real e a trajetória estimada, identificando o desvio padrão entre elas.

Na primeira trajetória, o robô móvel demarca o caminho percorrido por meio de um pincel, para quadro branco, de cor azul. Nas demais trajetórias, o robô demarca o caminho percorrido por meio de um pincel, também para quadro branco, de cor vermelha. Sendo assim, a cor azul representa a trajetória real e a cor vermelha a trajetória estimada por Odometria. A diferenciação de cores foi fundamental para compreender as distorções que podem ocorrer quando um robô móvel se locomove em suas missões de navegação. 
V Congresso Brasileiro de Informática na Educação (CBIE 2016)

Anais do XXVII Simpósio Brasileiro de Informática na Educação (SBIE 2016)

A captura de valores para a odometria ocorreu por meio do servo-motor interativo do próprio kit LEGO, cujo o mesmo possui um sensor de rotação interno. A resposta rotacional permite ao NXT controlar movimentos em torno do eixo da roda. O sensor de rotação embutido mede as rotações do motor em graus (precisão de $+/$ - um grau) ou as rotações completas.

O robô móvel foi submetido a dois tipos de circuitos fechados (com trajetória no sentido anti-horário). O primeiro circuito consistiu em um círculo, medindo cerca de $60 \mathrm{~cm}$ de diâmetro. O segundo consistiu em um circuito oval, medindo $90 \mathrm{~cm}$ de comprimento com curvas acentuadas à esquerda medindo em torno de $60 \mathrm{~cm}$, conforme demonstra a Figura 3.

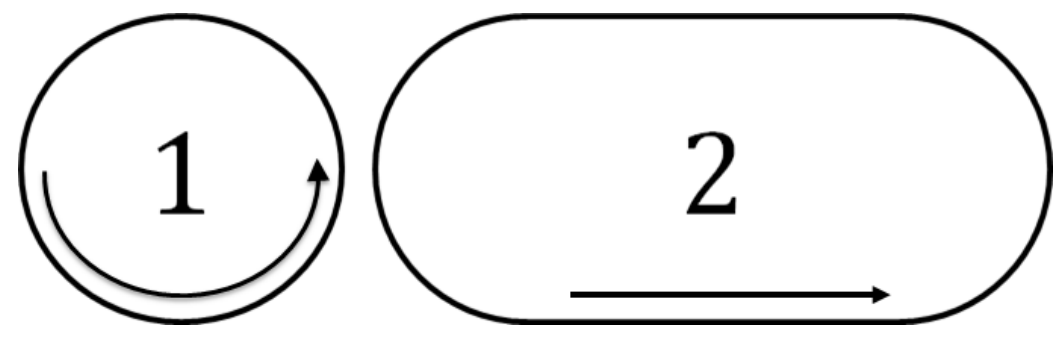

Figura 3. Demonstração dos Circuitos Fechados Propostos.

A linguagem de programação utilizada para a implementação do robô móvel foi a NXC (Not eXactly C), trata-se de uma linguagem de programação, similiar a linguagem $\mathrm{C}$, especialmente designada para os robôs Lego. Para o ambiente de desenvolvimento da programação, foi utilizado o Bricx Command Center (BricxCC - Centro de Comando Bricx) ambiente de desenvolvimento integrado (IDE - Integrated Development Environment) que possibilita escrever programas e fazer o upload destes para o sistema computacional do robô.

A visão geral do sistema proposto pode ser observada por meio da Figura 4. É possível notar que o Robô Móvel deve percorrer um Circuito Fechado com o objetivo de capturar as rotações em torno do eixo da roda (por meio do Sensor de Rotações do servo-motor), o valor rotacional é então analisado pelo Agente Odometria (programado no próprio robô), que determina o comportamento e a performance do Robô Móvel na realização das próximas trajetórias.

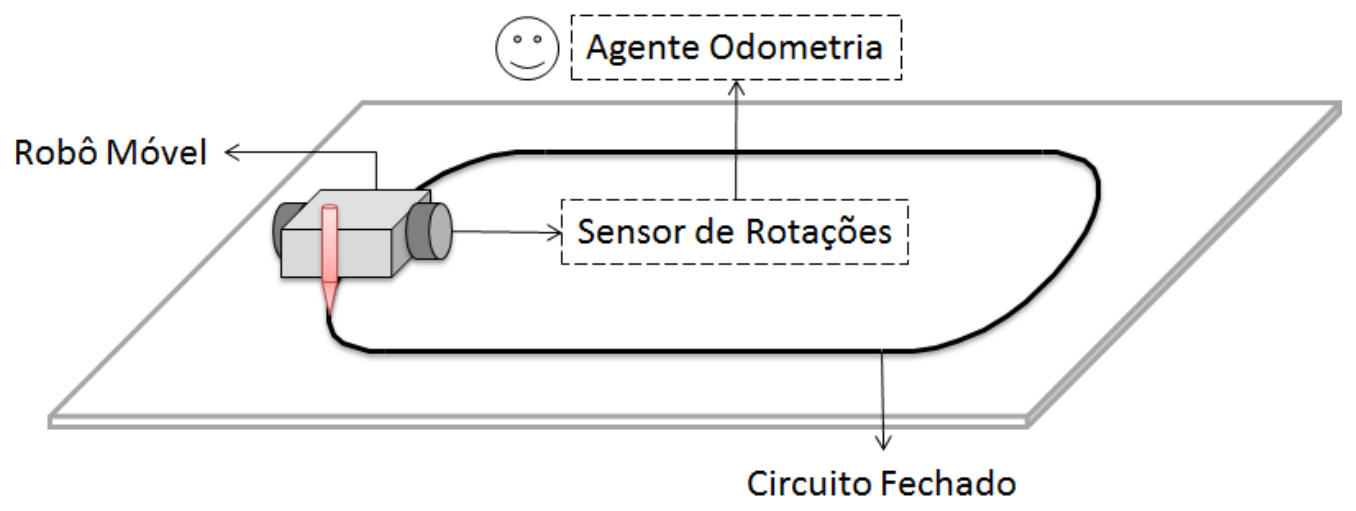

Figura 4. Visão Geral do Sistema Proposto. 
V Congresso Brasileiro de Informática na Educação (CBIE 2016)

Anais do XXVII Simpósio Brasileiro de Informática na Educação (SBIE 2016)

Para que os dois servo-motores (A e C), que movimentam as rodas do robô móvel, possam desenvolver o trajeto determinado em sincronia, foi utilizado o comando OnFwdReg(OUT_AC,50,OUT_REGMODE_SYNC); cujo mesmo é responsável por mover os servo-motores A e $\mathrm{C}$ para frente, numa velocidade de 50 (em uma escada de 0 a 100) e com sincronismo entre os ambos.

O sincronismo é ideal em robôs móveis que necessitem de precisão na navegação robótica, tendo em vista que, sem esta função pode ocorrer de um servo-motor desenvolver mais que outro, mesmo que ambos recebam o mesmo comando. O recurso de sincronização permite que os servo-motores selecionados rodem juntos e esperem um pelo outro caso um deles fique lento ou bloqueado.

\section{Resultados e Discussão}

Os resultados desta pesquisa estão organizados em duas Subseções: Análise dos Experimentos, apresentando os resultados dos experimentos práticos realizados por meio dos materiais e métodos propostos; e Levantamento Pós-Teste, apresentando dados estatísticos sobre a avaliação das tarefas por meio de Odometria, o método de localização relativa utilizado nos circuitos apresentados.

\subsection{Análise dos Experimentos}

Os experimentos foram realizados diversas vezes, cada circuito fechado recebeu um quantidade expressiva de testes e, considerando a variação obtida entre todos os testes, foi possível estabelecer uma margem de erro entre a trajetória real, percorrida durante a primeira volta completa do robô móvel, e a trajetória estimada por odometria, percorrida durante as próximas 3 (três) voltas completas do robô móvel com base nos valores obtidos dos sensores de rotação (encoders incremental). A Figura 5 apresenta uma instância do comportamento do robô móvel no circuito oval.

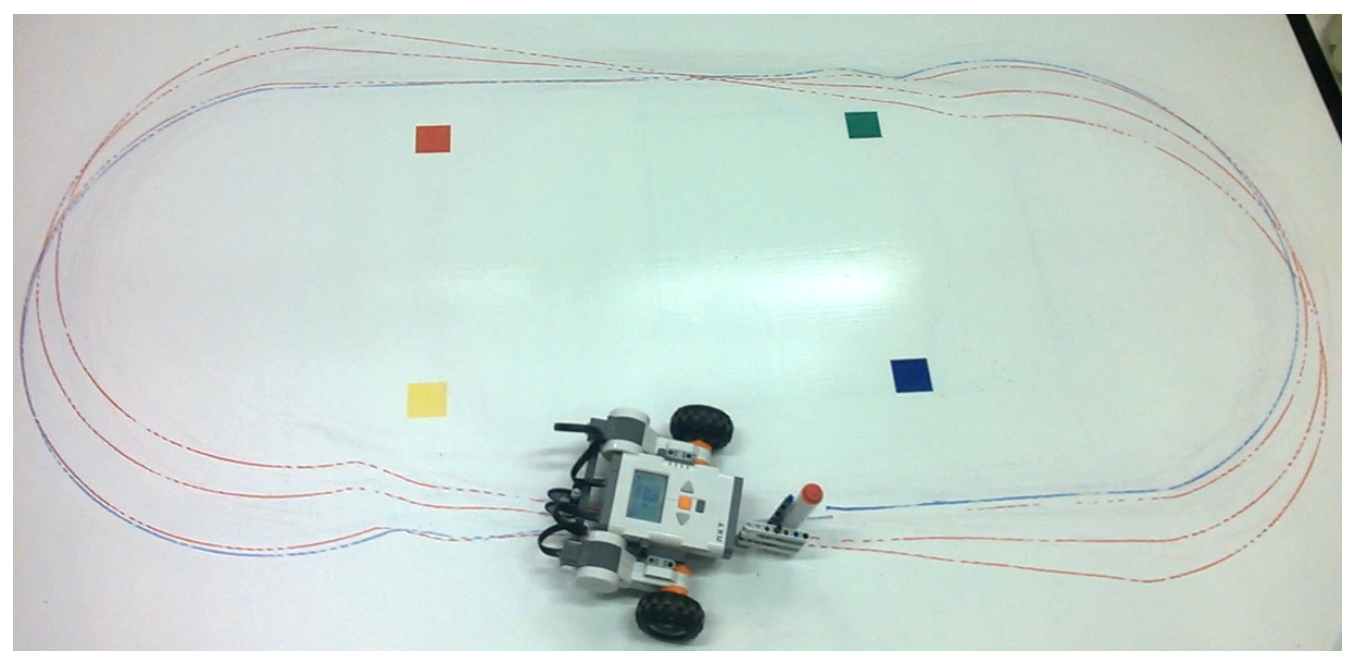

Figura 5. Comportamento do Robô Móvel nos Experimentos do Circuito Oval.

Para a representação das trajetórias, tanto nos experimentos como nos gráficos gerados, a cor azul representa a trajetória real percorrida pelo robô móvel, ao completar a primeira volta no circuito. A cor vermelha representa as trajetórias estimadas com base nos valores de odometria, obtidos pelos sensores de rotação. 
V Congresso Brasileiro de Informática na Educação (CBIE 2016)

Anais do XXVII Simpósio Brasileiro de Informática na Educação (SBIE 2016)

Os gráficos de resultados apresentam duas coordenadas: X e Y. O eixo X apresenta a distância real percorrida percorrida pelo robô móvel em centímetros e o eixo Y apresenta a distância estimada, calculada pelo robô móvel, por meio do método de localização relativa - Odometria, também em centímetros.

O resultado dos experimentos no circuito circular pode ser observado conforme a Figura 6. O desvio padrão observado durante os testes foi de uma perda de distância de $0,45 \%$, cerca de 4 milímetros, a cada volta entre a trajetória real e a estimada, em uma distância total de 105 centímetros em cada volta completada.

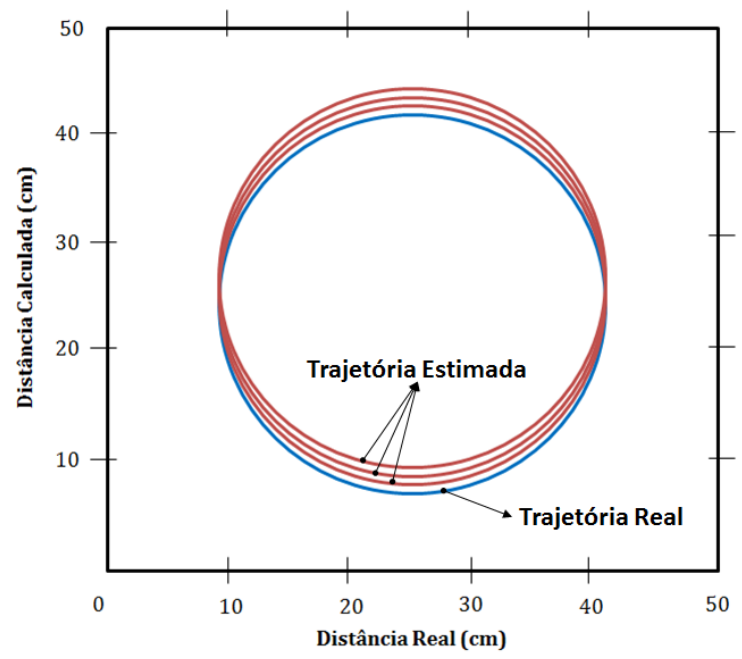

Figura 6. Circuito Circular - Trajetória Real(Azul) e Trajetória Estimada(Vermelho).

O resultado dos experimentos no circuito oval pode ser observado conforme a Figura 7. O desvio padrão observado durante os testes, foi uma perda de distância de $1,08 \%$, cerca de 23 milímetros, a cada volta entre a trajetória real e a estimada, em uma distância total de 220 centímetros em cada volta completada.

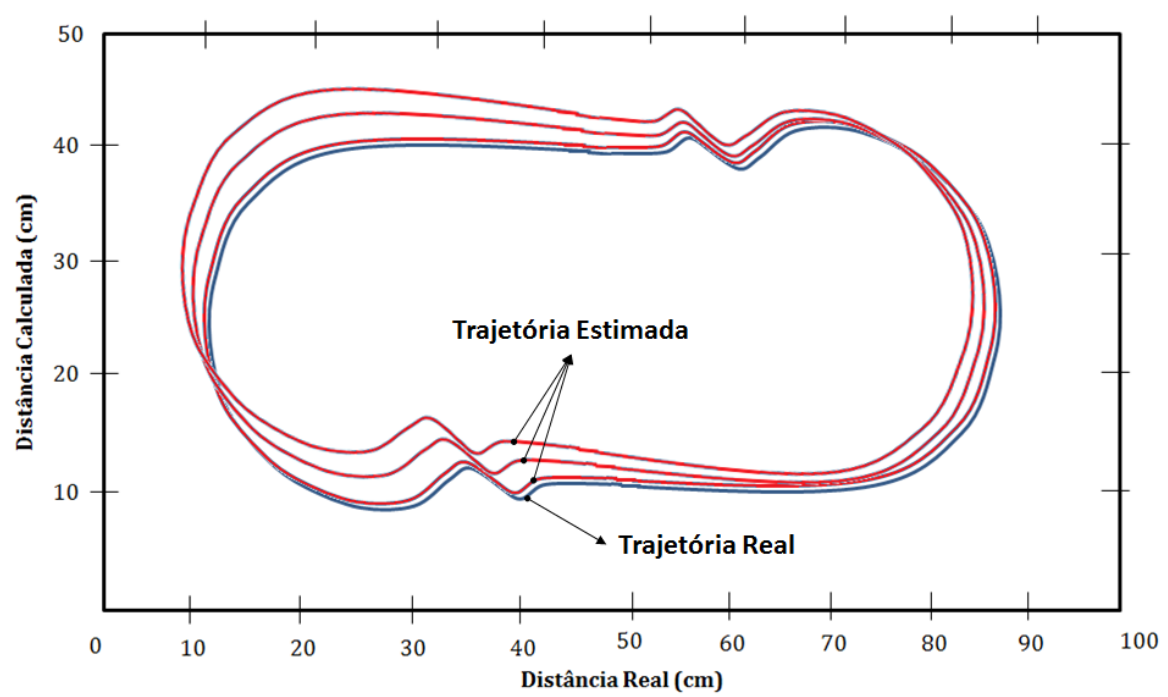

Figura 7. Circuito Oval - Trajetória Real(Azul) e Trajetória Estimada(Vermelho). 
V Congresso Brasileiro de Informática na Educação (CBIE 2016)

Anais do XXVII Simpósio Brasileiro de Informática na Educação (SBIE 2016)

Os ruídos apresentados ao final de cada curva (no sentido anti-horário), no circuito oval, acontecem por causa da tentativa de sincronizar os dois servo-motores, tendo em vista que, ao realizar a curva, os valores das rotações, entre os servo-motores, devem ser distintos. No entanto, ao completar a curva os dois servo-motores devem retornar a situação de sincronia.

\subsection{Levantamento Pós-Teste}

O levantamento pós-teste foi mensurado com base nos resultados obtidos por meio dos experimentos práticos com o Kit Lego Mindstorms NXT 2.0, avaliando a acurácia da Odometria em ambientes de tarefas na Robótica Educacional, levando em consideração dois quesitos:

1. Eficiência da Odometria conforme a distância percorrida no ambiente de tarefa (circuito fechado);

2. Fatores de dependência da Odometria para aquisição de resultados satisfatórios (conforme plataforma robótica utilizada).

A Figura 8 apresenta o gráfico de eficiência da Odometria conforme a distância percorrida. Neste levantamento foi possível observar que, com cerca de $200 \mathrm{~cm}$ percorridos pelo robô móvel, a precisão de estimativa da odometria atinge $99 \%$ de acerto. Quando o robô móvel aproxima-se de $600 \mathrm{~cm}$ percorridos, a precisão da Odometria diminui, atingindo 97\% de acerto. Quando o robô móvel chega em $1000 \mathrm{~cm}$ percorridos, a precisão da Odometria diminui para 95\% de acerto. E, por fim, quando o robô móvel atinge de 2000 cm percorridos, a precisão da Odometria diminui para $90 \%$ de acerto.

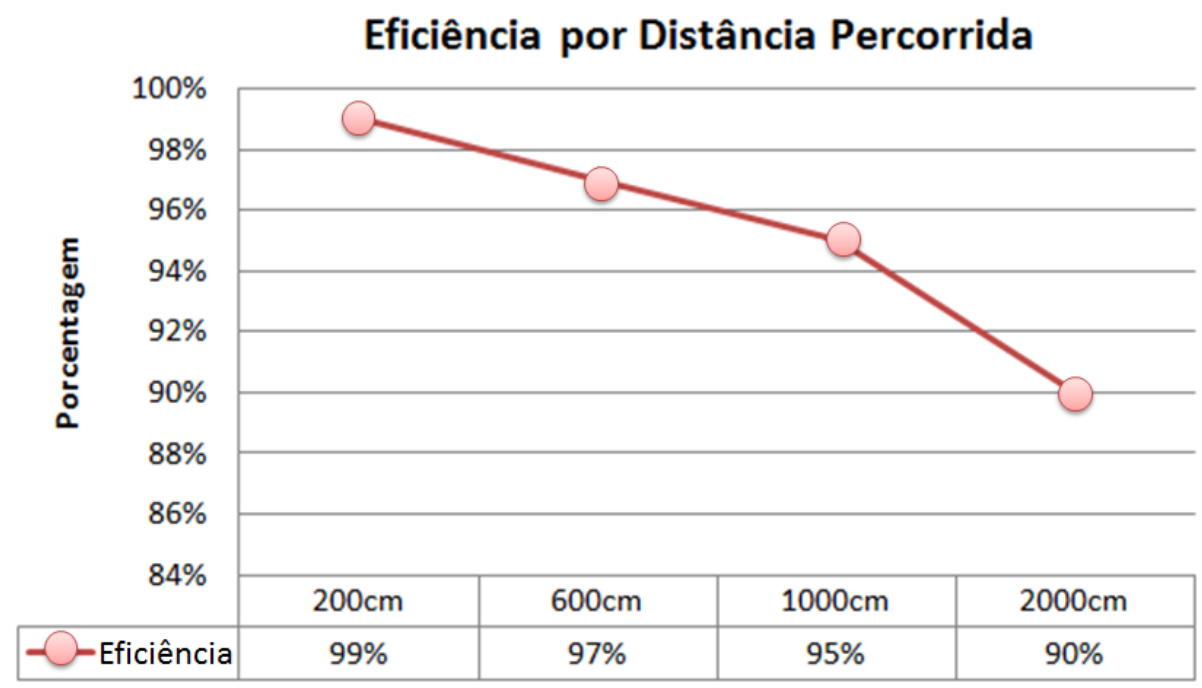

Figura 8. Gráfico de Eficiência da Odometria por Distância Percorrida.

É possível constatar que, a medida que o robô móvel se locomove no ambiente de tarefa, a taxa de acerto da Odometria diminui gradativamente. Levando em consideração que os ambientes de robótica educacional são, normalmente, planos e consideravelmente pequenos, a Odometria pode ser considerada um método eficiente para monitorar a trajetória e o comportamento robótico, podendo ainda receber cálculos para correções da trajetória visando aumentar a precisão desta técnica. 
V Congresso Brasileiro de Informática na Educação (CBIE 2016)

Anais do XXVII Simpósio Brasileiro de Informática na Educação (SBIE 2016)

A Figura 9 apresenta o gráfico de dependências da Odometria com base em três fatores: servo-motor, ambiente de tarefa e carga de bateria. Nesse contexto, uma entrevista com 5 (cinco) equipes de roboticistas Lego apontou que há uma dependência de cerca $96 \%$ do servo-motor utilizado no robô móvel para determinar a performance da Odometria. Da mesma forma, foi identificado que existe cerca de $85 \%$ de dependência do ambiente de tarefa proposto para navegação. E, por fim, foi apontado que existe cerca de $98 \%$ de dependência do nível de carga da bateria.

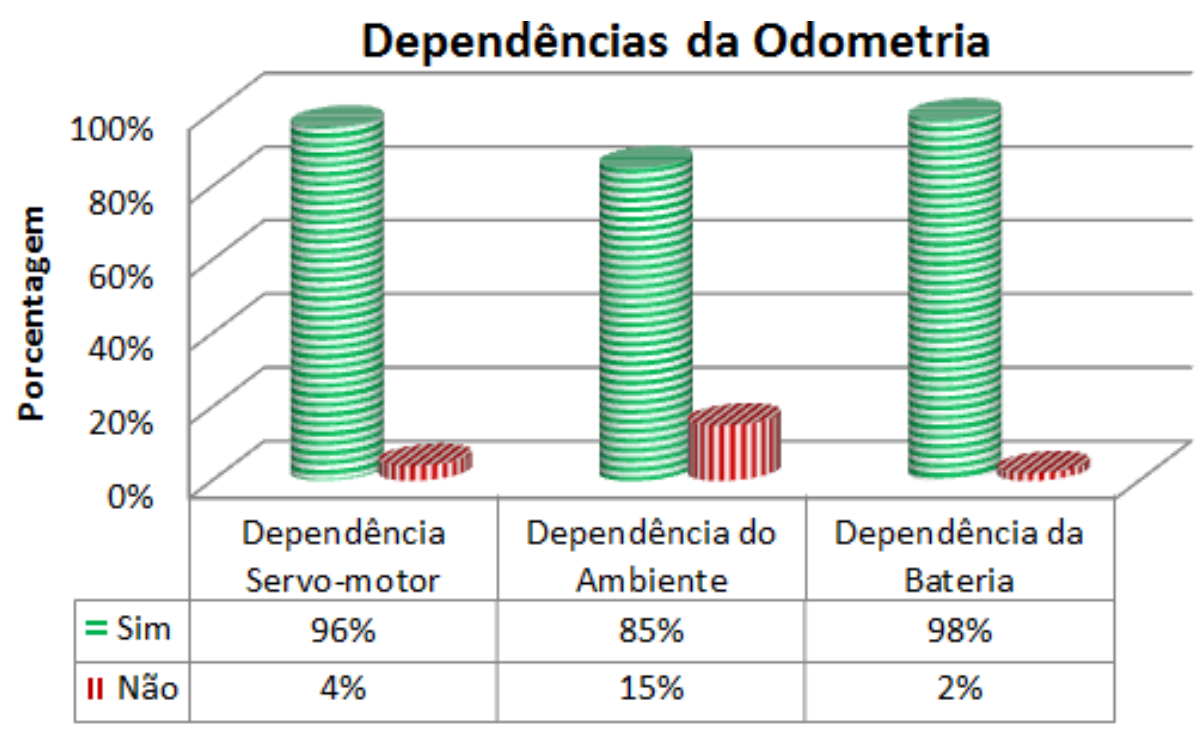

Figura 9. Gráfico de Dependências da Odometria.

Com base neste levantamento foi possível constatar que a acurácia da Odometria depende fortemente da plataforma robótica na qual está submetida. De modo geral, os levantamentos mostraram que a Odometria é um método simples, mas que varia conforme a utilização da estrutura do robô móvel e do ambiente de tarefa.

\section{Conclusões}

Este trabalho investigou um método de localização que permitisse computar a trajetória percorrida pelo robô móvel na realização de circuitos fechados, tendo como premissa a necessidade de analisar o comportamento robótico em ambientes educacionais presenciais ou a distância. Em Laboratórios Remotos de Robótica Educacional esta técnica, associada aos procedimentos avaliativos de uma determinada tarefa, pode permitir uma melhoria no processo de aprendizagem dos alunos, pois apresenta um mapeamento da trajetória percorrida pelo robô móvel em um dado cenário.

Além disso, ao sistema computacional do robô móvel foi desenvolvido um agente inteligente com a capacidade de analisar os valores rotacionais em torno do eixo da roda. É possível expandir esta funcionalidade enviando, por bluetooth, as informações de Odometria para um sistema servidor, com o objetivo de reconstruir a trajetória realizada pelo robô móvel. Nesse sentido, professores e alunos que antes não tinham nenhum tipo de feedback do comportamento robótico, com esta técnica, é possível criar situações que favoreçam a aprendizagem por meio do comportamento robótico.

As limitações desta pesquisa está vinculada a plataforma robótica do Kit Lego Mindstorms NXT 2.0, que apresenta limitações no processo de percepção (sensores de 
V Congresso Brasileiro de Informática na Educação (CBIE 2016)

Anais do XXVII Simpósio Brasileiro de Informática na Educação (SBIE 2016)

rotação) e na precisão dos atuadores (servo-motores). Os experimentos mostraram que a trajetória estimada sofreu distorções que variaram conforme a distância percorrida e a fatores mecânicos do robô. Também foi possível constatar que os erros de Odometria são acumulativos e sistemáticos, sofrendo interferência da imprecisão dos sensores de rotação e do nível de carga da bateria.

Como trabalhos futuros, pretende-se estudar os métodos híbridos de localização, associando o uso do método de localização relativa (Odometria) com o método de localização absoluta (processamento de imagem) para monitorar e analisar o comportamento de robôs móveis em ambientes de Robótica Educacional.

\section{Referências}

Benedettelli, D. (2007). Programming LEGO NXT Robots Using NXC. Revision: John Hansen, Version 2.2.

Bezerra, C., Alsina, P., and Medeiros, A. (2003). Um Sistema De Localização Para Um Robô Móvel Baseado Em Odometria e Marcos Naturais. Simpósio Brasileiro de Automação Inteligente - SBAI.

Bezerra, C., Alsina, P., and Medeiros, A. (2004). Localização de Um Robô Móvel Usando Odometria e Marcos Naturais. Dissertação de Mestrado - UFRN.

Borenstein, J., Everett, H. R., and Feng, L. (1996). Where am I? Sensors and Methods For Mobile Robot Positioning. The University of Michigan.

Carvalho, J., Molina, L., Bensebaa, K., Carvalho, E., and Freire, E. (2009). Estimação de Posição e Orientação para Robôs Móveis. Simpósio Brasileiro de Automação Inteligente - SBAI.

Fiorio, R., Esperandim, R. J., Silva, F. A., Varela, P. J., Leite, M., and Reinaldo, F. (2014). Uma Experiência Prática da Inserção da Robótica e Seus Beneficios como Ferramenta Educativa em Escolas Públicas. Simpósio Brasileiro Informática na Educação - SBIE.

Heinen, E., Krynski, E. M., Marczal, D., and Filho, P. L. (2015). RASPIBLOCOS: Ambiente de Programação Didático Baseado em Raspberry Pi e Blockly. Simpósio Brasileiro de Informática na Educação - SBIE.

Kee, D. (2015). Damien Kee - Technology in Education. http://www.damienkee.com/. Acessado em: 09-12-2015.

Martins, R., Bueno, S., Mirisola, L., Paiva, E., and Ferreira, P. (2011). Cinemática e Localização em Robótica Terrestre Usando Múltiplos Encoders. Simpósio Brasileiro de Automação Inteligente - SBAI.

Pio, J. L. d. S., de Castro, T. H. C., and Júnior, A. N. d. C. (2006). A Robótica Móvel como Instrumento de Apoio à Aprendizagem de Computação. Simpósio Brasileiro de Informática na Educação - SBIE.

Thrun, S., Burgard, W., and Fox, D. (2005). Probabilistic Robotics (Intelligent Robotics and Autonomous Agents). The MIT Press.

Tonouchi, Y., Tsubouchi, T., and Arimoto, S. (1994). Fusion of Dead-Reckoning Positions With a Workspace Model for a Mobile Robot by Bayesian Inference. International Conference on Intelligent Robots and Systems. 